\title{
Kidney transplantation from small pediatric donors may be feasible to those who developed chronic refractory dialysis hypotension: a single-center experience
}

\author{
Lu Zheng ${ }^{1,2,3,4,5}$, Hanying Jia ${ }^{1,2,3,4,5}$, Rending Wang ${ }^{1,2,3,4,5}$, Wenhan Peng ${ }^{1,2,3,4,5}$, Junhao Lv $\mathbf{~ v}^{1,2,3,4,5}$, \\ Wenhua Lei ${ }^{1,2,3,4,5}$, Guangjun Liu ${ }^{1,2,3,4,5}$, Yu Cui ${ }^{1,2,3,4,5}$, Jianghua Chen ${ }^{1,2,3,4,5}$, Jianyong $\mathbf{W u}^{1,2,3,4,5}$
}

${ }^{1}$ Kidney Disease Center, the First Affiliated Hospital, College of Medicine, Zhejiang University, Hangzhou, China; ${ }^{2}$ Key Laboratory of Nephropathy, Zhejiang Province, Hangzhou, China; ${ }^{3}$ Kidney Disease Immunology Laboratory, the Third-Grade Laboratory, State Administration of Traditional Chinese Medicine of China, Hangzhou, China; ${ }^{4}$ Key Laboratory of Multiple Organ Transplantation, Ministry of Health of China, Hangzhou, China; ${ }^{5}$ Institute of Nephropathy, Zhejiang University, Hangzhou, China

Contributions: (I) Conception and design: L Zheng, H Jia, J Chen, J Wu; (II) Administrative support: J Wu; (III) Provision of study materials or patients: J Wu, J Lv, W Lei; (IV) Collection and assembly of data: L Zheng, H Jia, J Lv, W Lei; (V) Data analysis and interpretation: L Zheng, R Wang, W Peng, G Liu, Y Cui; (VI) Manuscript writing: All authors; (VII) Final approval of manuscript: All authors.

Correspondence to: Jianyong Wu. Kidney Disease Center, the First Affiliated Hospital, College of Medicine, Zhejiang University, Qingchun Road 79, Hangzhou, China. Email: wujianyong1964@zju.edu.cn.

Background: Chronic refractory dialysis hypotension $(\mathrm{CRDH})$ is a serious issue in dialysis patients waiting for transplants. It leads to fatal clinical outcomes and disqualification from kidney transplantation. Kidney transplantation from pediatric donor to adult patient with lower blood pressure (BP) may be an option. No related study has been reported and we conducted this study to first evaluate the effect of pediatric donor kidney transplantation in CRDH recipients.

Methods: Ten single-kidney transplantations from small pediatric donors after cardiac death in our center between August 2016 and April 2018 were described. Half were CRDH recipients (group A) with intradialytic and interdialytic systolic blood pressure (SBP) below $100 \mathrm{mmHg}$. Each was paired with no$\mathrm{CRDH}$ recipient (control, group B) from the same donor. The operation method of vascular anastomosis and ureterocystoneostomy was the same as that of adult donors. Clinical characteristics, post-operative treatment and outcomes of all recipients were retrieved. Postoperative BP, graft function and size were compared between two groups. The follow-up time was up to April 2019.

Results: There was no acute rejection (AR), graft loss or death in all recipients after transplantation. Their renal function was recovered despite three transient delayed graft function (DGF). There was no significant difference in serum creatinine ( $\mathrm{SCr})$ or graft size $(\mathrm{P}=0.84,0.94)$ after transplantation between two groups. For all CRDH recipients, the postoperative SBP was above $100 \mathrm{mmHg}$ (except one, 90-130 $\mathrm{mmHg}$ ). The BP one year after transplantation was maintained at 110-125/70-85 $\mathrm{mmHg}$.

Conclusions: kidney transplantation from small pediatric donors may be feasible to CRDH recipients and their BP may return to normal after transplantation.

Keywords: Chronic refractory dialysis hypotension (CRDH); pediatric donor; kidney transplantation; blood pressure (BP); graft function

Submitted Jan 05, 2020. Accepted for publication May 09, 2020.

doi: $10.21037 / \mathrm{atm}-20-304$

View this article at: http://dx.doi.org/10.21037/atm-20-304 


\section{Introduction}

Kidney transplantation is preferred in the treatment of endstage renal disease (ESRD). However, the disparity between the intense requirement for kidneys and the inadequate supply of available donor organs remains a prominent issue despite of an increasing number of transplantations all over the world. Consequently, the number of kidney transplantation from pediatric donors has been increasing, which contributes to the expansion of the donor pool $(1,2)$.

Even though pediatric donor kidney transplantation could lead to ureteral (stenosis or leakage), vascular (venous thrombosis or arterial stenosis) complications, delayed graft function (DGF) and acute rejection (AR) (1,3-6), recipients of pediatric donor kidneys have got satisfying long-term outcomes similar to those received adult donor kidneys within standard criteria (2,4,7-12). Pediatric donors are used mostly for pediatric recipients and some for adult recipients. However, one of the prerequisites of the adult recipient is the controllable high blood pressure (BP) with less than or equal to two antihypertensive drugs and postoperative high BP should be strictly controlled (13). Maintaining lower $\mathrm{BP}$ after transplantation is of great importance for pediatric kidney to prevent hyperfiltration injury. On the other hand, recipients with chronic refractory dialysis hypotension $(\mathrm{CRDH})$ may not provide adequate blood perfusion for adult kidney because of severe hypotension. CRDH patients are therefore, just fit the criteria as the recipients of pediatric kidney.

Patients waiting for transplants on long-term dialysis may develop intradialytic hypotension (IDH). The definitions of IDH remain various and controversial. According to the National Kidney Foundation, IDH is defined as a decrease in systolic blood pressure (SBP) by $\geq 20 \mathrm{mmHg}$ or a decrease in mean arterial pressure by $\geq 10 \mathrm{mmHg}$ with clinical symptoms (14). Notably, there is one special form of IDH in $5-10 \%$ of dialysis patients, CRDH, defined as sustained $\mathrm{SBP}<100 \mathrm{mmHg}$ during both intradialytic and interdialytic period generally $(15,16)$. CRDH is a severe type of dialysisrelated hypotension and a sign of poor prognosis in dialytic patients. It may lead to disqualification from kidney transplantation (15-19). These CRDH patients have less chance of transplantation and there has been only a few successful transplant cases from adult donors (15,16,20-22). For these transplant recipients with $\mathrm{CRDH}$, the BP remains hard to be maintained at a stable level and the recovery of graft function is difficult after transplantation $(15,16,20,21)$.

Currently, there has been no study on pediatric donor kidney transplantation to CRDH recipients. We held the view that kidney transplantation from small pediatric donors may be feasible to those who developed CRDH. Pediatric kidney may improve BP of CRDH patients and perform normal renal function after transplantation. We therefore performed five small pediatric donor kidney transplantations for CRDH recipients in our center and reported our experience in this article.

We present the following article in accordance with the STROBE reporting checklist (available at http://dx.doi. org/10.21037/atm-20-304).

\section{Methods}

In this retrospective study, we described ten single-kidney transplantations (group A, 5 kidneys were transplanted to CRDH adults, cases 1-5; group B, 5 to regular end-stage renal failure, controls 1-5) from five small pediatric donors of cardiac death donation in our Kidney Disease Center between August 2016 and April 2018. The median age of 5 donors was 28 [11-51] months old and median body weight was 13 [12-20] kg. Their median level of serum creatinine (SCr) was 44 [19-312] $\mu \mathrm{mol} / \mathrm{L}$ at transplantation and blood type was consistent with that of recipients. The cause of donor death was aspiration pneumonitis (1 case), fall from a height (1 case) or craniocerebral trauma by accident (3 cases). Among ten recipients (seven females and three males), half were CRDH (group A). $\mathrm{CRDH}$ was defined as follows: the SBP was declined $\geq 20 \mathrm{mmHg}$ and sustained below $100 \mathrm{mmHg}$ after dialysis with a history of hypertension before dialysis and related clinical symptoms. Each of CRDH recipients was paired with one control from the same deceased pediatric donor. The SBP of all the controls (group B) was constantly above $100 \mathrm{mmHg}$ during dialysis. The median age was 49 [38-64] years old in group A and 33 [5-55] in group B. Nobody had ever developed diabetes, cardiovascular events or cancer. The clinical characteristics of donors and recipients are listed in Table 1. The operation method of vascular anastomosis and ureterocystoneostomy was the same as that of adult donors. The follow-up time was up to April 2019 (all $\geq$ 1 year after transplantation). This study was approved by the Ethics Committee of the First Affiliated Hospital, College of Medicine, Zhejiang University (NO.: 20191491) and informed consent was taken from all the patients. All donor kidneys in this study were procured from donation after the citizens' death in accordance with the guidelines of The National Program for Deceased Organ Donation in 
Table 1 Characteristics of donors and recipients (including post-operative treatment and outcomes)

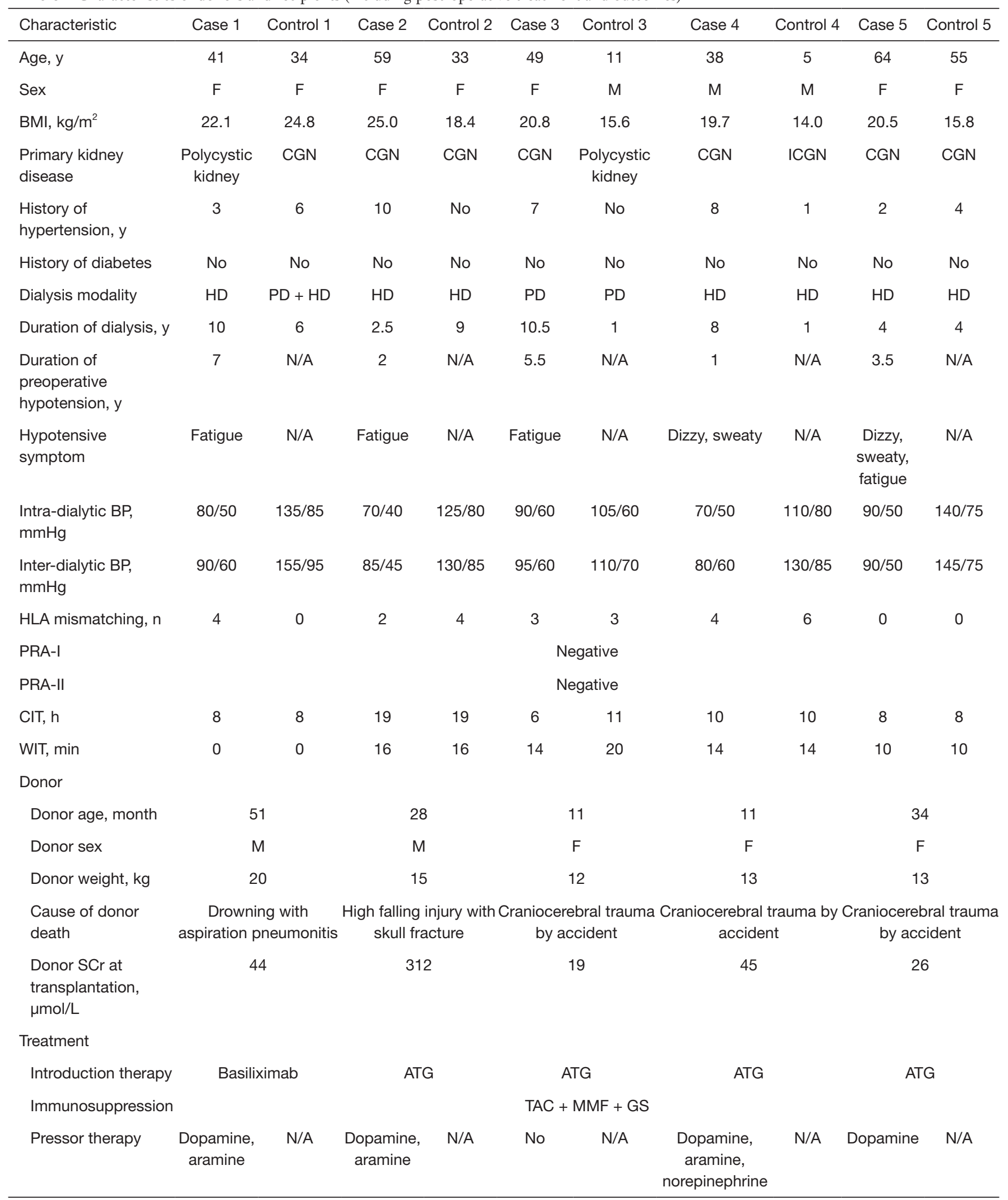

Table 1 (continued) 
Table 1 (continued)

\begin{tabular}{|c|c|c|c|c|c|c|c|c|c|c|}
\hline Characteristic & Case 1 & Control 1 & Case 2 & Control 2 & Case 3 & Control 3 & Case 4 & Control 4 & Case 5 & Control 5 \\
\hline \multicolumn{11}{|l|}{ Outcome } \\
\hline DGF & Yes & No & No & No & Yes & Yes & No & No & No & No \\
\hline $\begin{array}{l}\mathrm{BP} \text { at } 12 \text { months } \\
\text { after transplantation, } \\
\mathrm{mmHg}\end{array}$ & $110 / 70$ & $135 / 85$ & $120 / 85$ & $110 / 70$ & $125 / 85$ & $125 / 75$ & $115 / 85$ & $115 / 75$ & $125 / 75$ & $110 / 70$ \\
\hline Graft loss & No & No & No & No & No & No & No & No & No & No \\
\hline Death & No & No & No & No & No & No & No & No & No & No \\
\hline
\end{tabular}

ATG, anti-thymocyte globulin; BMI, body mass index; BP, blood pressure; CGN, chronic glomerulonephritis; CIT, cold ischemia time; DGF, delayed graft function; GS, glucocorticoids; HD, hemodialysis; HLA, human leukocyte antigen; ICGN, immune complex-mediated glomerulonephritis; MMF, mycophenolate mofetil; N/A, not applicable; PD, peritoneal dialysis; PRA, panel reactive antibodies; SCr, serum creatinine; TAC, tacrolimus; WIT, warm ischemia time.

China. The pediatric donor grafts were donated to the Red Cross Society of Zhejiang Province and allocated to our center by the China Organ Transplant Response System (COTRS). All donations were voluntary, unpaid, and in compliance with the Declaration of Helsinki and no organs were obtained from prisoners.

The clinical characteristics of the ten recipients, such as age, sex, primary disease and duration and modality of dialysis etc. were retrieved from the kidney transplantation database and electronic medical record system in our hospital. We also retrieved the data on the treatment after kidney transplantation, which included induction therapy (Basiliximab or anti-thymocyte globulin, ATG), triple immunosuppressive regimen (all used tacrolimus, mycophenolate mofetil and glucocorticoids, TAC + MMF + GS) and pressor therapy (dopamine, aramine and/or norepinephrine). Postoperative pressor therapy was as follows: Three (case 1, 2, 4) received dopamine infusion at a dose of $0.8-12 \mu \mathrm{g} / \mathrm{kg} / \mathrm{min}$ and aramine was given additionally at $0.08-1.4 \mu \mathrm{g} / \mathrm{kg} / \mathrm{min}$. One of them (case 4) used norepinephrine at $0.04-0.12 \mu \mathrm{g} / \mathrm{kg} / \mathrm{min}$ for $18 \mathrm{~h}$ at first. They stopped intravenous vasopressor on day 9 or 10 postoperatively. Case 5 only received a dopamine infusion at $0.8-6.9 \mu \mathrm{g} / \mathrm{kg} / \mathrm{min}$ for $14 \mathrm{~h}$ while case 3 didn't receive pressor therapy. Outcome indices included BP, graft function ( $\mathrm{SCr}$ ), graft size, the occurrence of DGF, AR or graft loss and survival during the follow-up. Graft size was regularly measured by ultrasonography and calculated according to the equation: $V=4 / 3 \pi r_{x} r_{y} r_{z}(23)$.
DGF was defined as the requirement for dialysis in the first postoperative week (24). We also longitudinally recorded the $\mathrm{BP}$ for $\mathrm{CRDH}$ patients in the whole process.

The value of $\mathrm{SCr}$ and graft size in two groups were compared by Student's $t$ test. $\mathrm{P}$ values $<0.05$ were considered statistically significant. SPSS 22.0 (SPSS, Inc., Chicago, IL, USA) was used for all statistical analyses.

\section{Results}

\section{Pre-transplant}

As shown in Table 1, 2 recipients had polycystic kidney; 1 had immune complex-mediated glomerulonephritis (ICGN) confirmed by kidney biopsy; the rests were diagnosed as chronic glomerulonephritis (CGN). In group A, four patients were on hemodialysis (HD) and one on peritoneal dialysis (PD); in group $\mathrm{B}$, three were on $\mathrm{HD}$, one on $\mathrm{PD}$, and one on PD to start and switched to HD. The median duration of dialysis was $8(2.5-10.5)$ years in group A and 4 [1-9] years in group B.

Prior to transplantation, four of the patients in group A used medication to control hypertension for 2 to 10 years and one didn't take anti-hypertension drug. The duration of preoperative hypotension varies from 1 to 7 years. All five CRDH patients had intra-dialytic SBP in the range 70$90 \mathrm{mmHg}$ and inter-dialytic SBP persistently below $100 \mathrm{mmHg}$. They all took the vasopressor drug midodrine three times a day, $2.5-5.0 \mathrm{mg}$ for each time, with poor effect. 


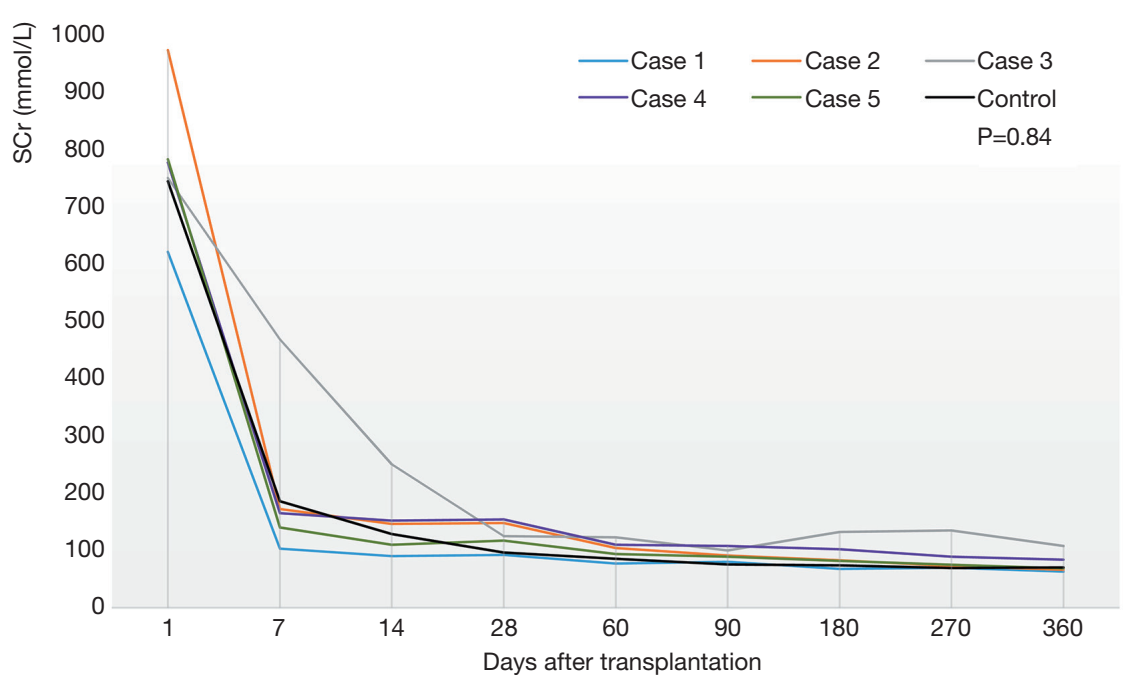

Figure 1 The change of serum creatinine (SCr) after transplantation in two groups. Figure 1 shows the changes of SCr after transplantation in two groups. The levels of SCr were recorded for all recipients 1, 7, 14, 28, 60, 90, 180 and 360 days after transplantation. The postoperative SCr in group A was listed respectively (case 1-5). The post-operative SCr in group B was expressed by the average SCr of four recipients because the other one (control 4) was a five-year-old child whose renal function recovered obviously better than others and SCr was much lower. There was no significant difference in serum creatinine between two groups (group A vs. group B, 191.24 $\pm 211.64 v s$. $169.94 \pm 205.82 \mu \mathrm{mol} / \mathrm{L}, \mathrm{P}=0.84)$.

One had kidney nephrectomy (case 1). She had unilateral (left) renal agenesis and experienced right kidney nephrectomy due to polycystic kidney rupture 7 years before transplantation. She maintained HD after the nephrectomy with intra-dialytic BP 80/50mmHg and inter-dialytic BP 90/60 mmHg. She and another patient (case 2) had fistula occlusions due to severe hypotension during dialysis. The SBP in group B was slightly decreased during dialysis but remained above $100 \mathrm{mmHg}$.

Panel reactive antibodies (PRA-I and PRA-II) were all negative before transplantation. Three patients in each group had moderate human leukocyte antigen (HLA) mismatch. Electrocardiogram and echocardiogram showed no heart disease in all patients. During operation, three patients (case 1, 2, 4) in group A whose $\mathrm{SBP} \leq 85 / 50 \mathrm{mmHg}$ received dopamine to maintain $\mathrm{SBP}$ to $110-120 \mathrm{mmHg}$. The median cold ischemia time (CIT) was 8 hours in group A and 10 in group B; the median warm ischemia time (WIT) was 14 minutes in both groups.

\section{Post-transplant}

Figure 1 showed the change of SCr after transplantation in two groups. All patients' renal function recovered well even though three suffered from transient DGF (2 in group $\mathrm{A}$ and 1 in group $\mathrm{B})$. The $\mathrm{SCr}$ of all decreased gradually and was below $90 \mu \mathrm{mol} / \mathrm{L}$ except one (case 3, $108 \mu \mathrm{mol} / \mathrm{L}$ ) one year after surgery. For case 3 , the $\mathrm{SCr}$ was stable at the level of $65 \mu \mathrm{mol} / \mathrm{L}$ two years after transplantation. There was no significant difference in $\mathrm{SCr}$ or graft size $(\mathrm{P}=0.84$, 0.94) during the follow-up between the two groups. For all, the urine volume recovered within two weeks after the operation and was all above $1,000 \mathrm{~mL} / \mathrm{d}$ on discharge. As depicted in Figure 2, the regular growth of the grafts was not affected by hypotension.

Figure 3 recorded the SBP fluctuation after transplantation in group A. Four patients (not case 3) in group A received pressor therapy immediately after operation to keep SBP between 110-120 mmHg. The BP of CRDH patients was obviously higher than that before the operation and the SBP was above $100 \mathrm{mmHg}$ with proper management after transplantation and maintained during the follow-up period (except case 1, 90-130 $\mathrm{mmHg}$ ). The average $\mathrm{BP}$ one year after transplantation was maintained at $110-125 / 70-85 \mathrm{mmHg}$. Patients in group B received antihypertensive agents to maintain post-operative BP at $100-120 / 60-80 \mathrm{mmHg}$ and kept $\mathrm{BP}$ at $110-135 / 70-85 \mathrm{mmHg}$ after discharge.

As mentioned above, one patient (case 3) who didn't receive pressor therapy after surgery maintained BP 120 130/80-90 $\mathrm{mmHg}$ after discharge. She appeared oliguric in four months after transplantation. Renal allograft 


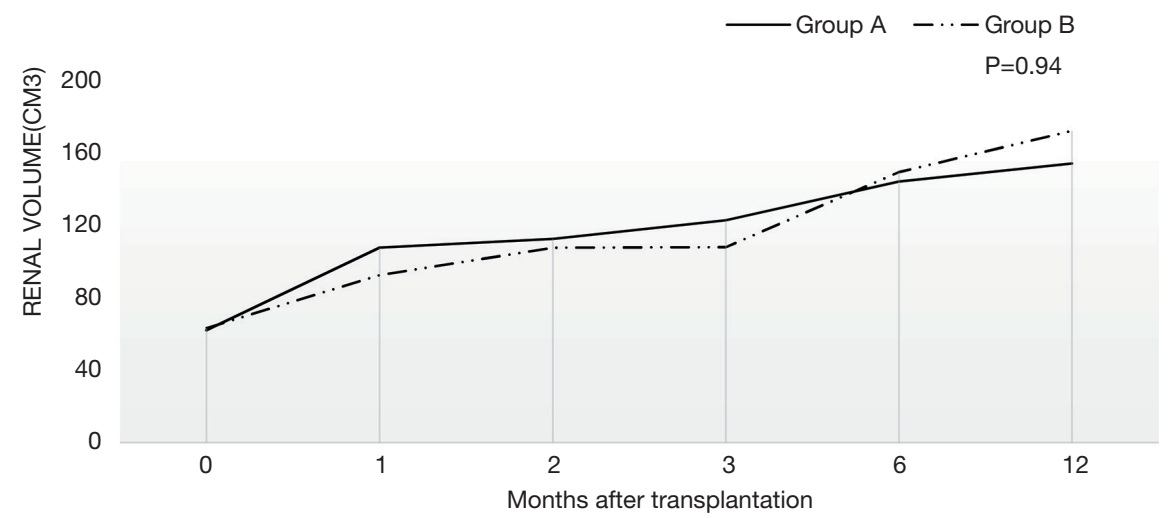

Figure 2 The change of graft size after transplantation in two groups. Figure 2 shows the change of graft size after transplantation in two groups. The graft size was recorded for all recipients at the transplantation and 1, 2, 3, 6, 12 months after transplantation. The two curves were the average graft size of two groups respectively. There was no significant difference in graft size between two groups (group A vs. group B $117.11 \pm 29.64$ vs. $\left.115.49 \pm 35.84 \mathrm{~cm}^{3}, \mathrm{P}=0.94\right)$.

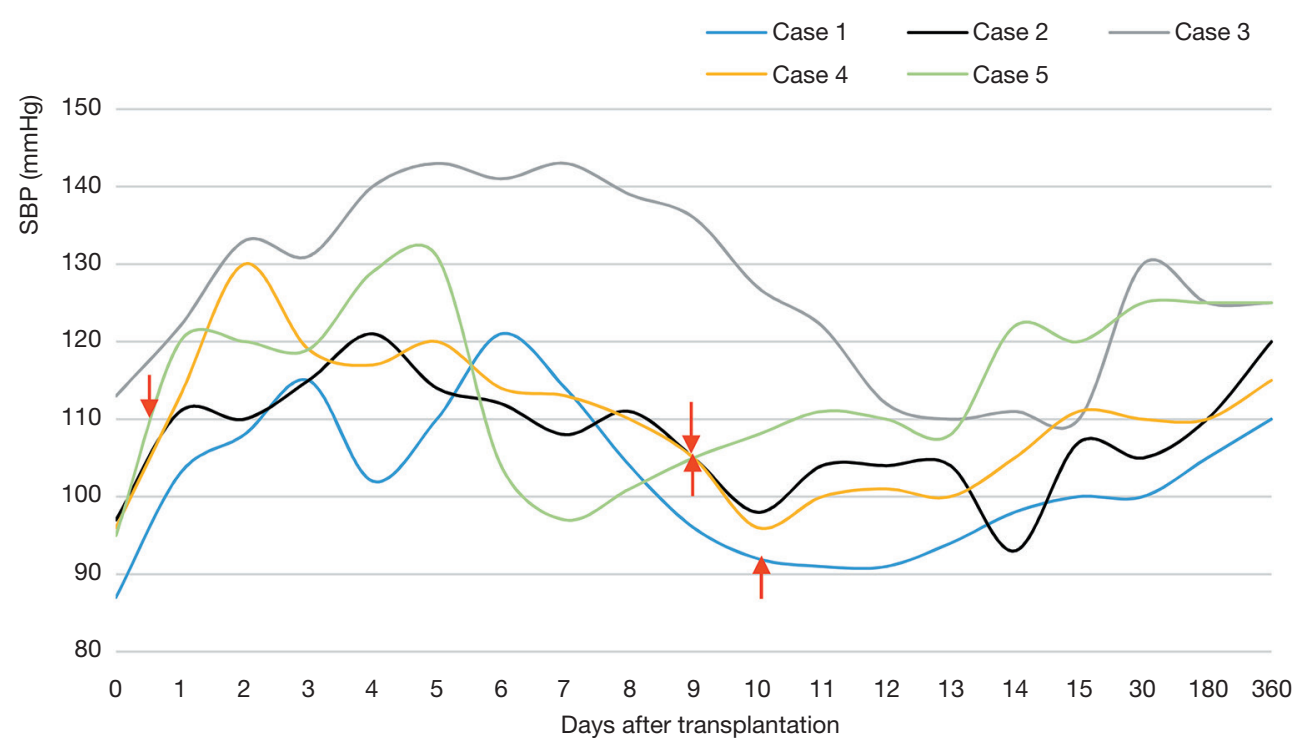

Figure 3 The change of SBP in group A after transplantation. Figure 3 shows the changes of systolic blood pressure (SBP) in group A after transplantation. The fluctuation of SBP tends to be narrower. The red arrows represent the time to stop intravenous vasopressors. The stop time was 10, 9 and 9 days after transplantation for case 1, 2 and 4 respectively. For case 5, she stopped 14 hours after surgery. Case 3 didn't receive any vasopressor.

B-mode ultrasound showed hypoechoic mass in the hilum of transplanted kidney, perirenal hematoma was suspected. Iliac artery CTA showed moderate to severe stenosis in the proximal segment of left allograft artery. She finally was diagnosed as fungal infection and allograft artery stenosis. After appropriate anti-infection therapy, her urine volume and SCr gradually normalized with reduced perirenal mass and improved stenosis.
During follow-up, no postoperative significant complications occurred in other patients and all ten recipients were alive with no AR or graft loss.

\section{Discussion}

As far as we know, this is the first study on pediatric donor kidney transplantation to the adult patients with CRDH. 
The graft function was recovered and $\mathrm{BP}$ was elevated back to normal. Our study demonstrated that pediatric donor kidney is suitable for the patients with CRDH.

Our CRDH patients had hypertension before dialysis and developed hypotension after long-time dialysis. The pathophysiology of CRDH is not yet well defined. However, a major cause for IDH is due to intravascular hypovolemia (17). Ultrafiltration during dialysis decreases central blood volume and cardiac output. Automatic dysfunction and blunted cardiovascular response to vasopressors may be the mechanisms of inter-dialytic hypotension (20). Another mechanism is the increased vasodilator which decreases peripheral resistance $(19,25)$. No-functional kidneys leading to the lack of sympathetic stimulus may be an additional cause of hypotension (for case 1). All these may be the reasons why our patients developed dialysis hypotension. These patients may advance to heart failure, severe vascular complications and even death without kidney transplantation $(15,18)$.

There has been no study on pediatric donor transplantation for CRDH patients. Only few transplant cases from adult donors to CRDH patients has been reported. Muscroft et al. reported eight transplant cases with dialysis-associated hypotension (15). All received living donor transplantation except one deceased donor. Even though the final result was satisfactory, only four of these recipients were CRDH, one of whom received deceased donor transplant and finally died of ischemic complications (15). In our center, two dialysis hypotension recipients underwent cardiac death adult donor transplants and received active vasopressor infusion during a long period after transplantation. They got poor outcome with both insufficient postoperative renal function and $\mathrm{BP}$ recovery. One had previous history of diabetes and the other suffered from radiofrequency ablation of ventricular premature beats and left nephrectomy of polycystic kidney before transplantation. Other cases mentioned in the literature have no such conditions. Donor type and preoperative condition of recipients might be the main reasons for the different outcomes. Other multiple reasons, such as preoperative evaluation and preparation, surgical technique, postoperative care and treatment, also might affect the outcome. Overall, transplantation of adult donor kidneys to $\mathrm{CRDH}$ recipients remain controversial.

As for pediatric donor transplantation, there are some potential hazards such as a higher vascular and urinary complication rates $(3,4,13)$ and a higher risk of $\mathrm{AR}$ and DGF $(4,14)$. It may also lead to hyperfiltration injury and graft failure due to inadequate nephrons $(6,12)$. The prerequisite of the pediatric kidney to adult recipient is that the $\mathrm{BP}$ of recipients is not too high. According to pediatric hypertension guidelines and other studies, the normal BP of children is $80-110 / 40-70 \mathrm{mmHg}$ for age $1-5$ years old which matches the BP of our dialysis patients (70-100/40$60 \mathrm{mmHg}$ around) (26-28). We think that the lower basal $\mathrm{BP}$ of pediatric donors needs to be maintained in recipients after transplantation and the lower BP of our patients with CRDH could exactly prevent the pediatric donor kidney from hyperfiltration injury. Meanwhile the gradual recovery of the graft function increases the $\mathrm{BP}$ of these recipients gradually. That is to say, these pediatric donor kidneys are used to a lower BP and can tolerate the lower BP in the recipients better. Therefore, we recommend small pediatric kidney to CRDH patients and we used low doses of postoperative vasopressors to keep the $\mathrm{BP}$ of the recipients not too high.

Generally speaking, we have got satisfying outcomes of transplanting pediatric kidneys to CRDH patients. The graft function of these CRDH recipients recovered well with gradual kidney growth after transplantation. The changes of BP after renal transplantation in CRDH patients remain unclear. Previous studies have suggested that blunted pressor responses and increased vasodilator production are associated with CRDH $(19,29)$. Sun et al. proposed that the renal allograft regulates the pressor response or the vasodilator production to normalize the BP of CRDH patients after transplantation (22). We also thought when graft function was established, the reninangiotensin-aldosterone system of the transplanted kidney plays an important role in increasing $\mathrm{BP}$ in $\mathrm{CRDH}$ patients.

Our study has some limitations. One of them is the case number. We attempt to increase the number of cases but in March of this year, the policy of organ-allocation system, COTRS, began to give the pediatric kidney to the priority population, the pediatric patients. Some other countries have the similar policy: according to The Eurotransplant Kidney Allocation System, pediatric patients are given priority for donors aged $<16$ years since 2010 $(30,31)$. Therefore, we have difficulties on this issue. It is recommended that the allocation policy should be revised and those dialysis-associated hypotension patients should be given opportunity to receive such transplantations. Second limitation is that we lack CRDH cases from adult donor transplantations as controls. However, in our center, there were merely two kidney transplants from adult donors after 


\section{Page 8 of 9}

cardiac death to IDH recipients as mentioned.

\section{Conclusions}

In conclusion, kidney transplantation from pediatric donors to adults with $\mathrm{CRDH}$ is feasible, the $\mathrm{BP}$ of patients was normalized after graft function was established. The guidelines for kidney transplantation haven't shown that CRDH is an absolute or relative contraindication/ indication for renal transplantation yet $(32,33)$. According to our research and experience, CRDH adults are suitable recipients of pediatric donor kidneys. Further studies regarding the effect of pediatric donor transplantation in CRDH recipients are eagerly needed.

\section{Acknowledgments}

We thank our colleagues at the Kidney Disease Center, the First Affiliated Hospital, College of Medicine, Zhejiang University for their support and assistance. In addition, we thank Professor Liu for his assistance in language editing. Funding: None.

\section{Footnote}

Reporting Checklist: The authors have completed the STROBE reporting checklist. Available at http://dx.doi. org/10.21037/atm-20-304

Data Sharing Statement: Available at http://dx.doi. org/10.21037/atm-20-304

Peer Review File: Available at http://dx.doi.org/10.21037/ atm-20-304

Conflicts of Interest: All authors have completed the ICMJE uniform disclosure form (available at http://dx.doi. org/10.21037/atm-20-304). The authors have no conflicts of interest to declare.

Ethical Statement: The authors are accountable for all aspects of the work in ensuring that questions related to the accuracy or integrity of any part of the work are appropriately investigated and resolved. We conducted this study in accordance with the principles of the Declaration of Helsinki. This study was approved by the Ethical Committee of the First Affiliated Hospital, College of Medicine, Zhejiang University (NO.:20191491) and informed consent was taken from all the patients. Written informed consent was obtained from the patient for publication of this study and any accompanying images. A copy of the written consent is available for review by the Editor-in-Chief of this journal.

Open Access Statement: This is an Open Access article distributed in accordance with the Creative Commons Attribution-NonCommercial-NoDerivs 4.0 International License (CC BY-NC-ND 4.0), which permits the noncommercial replication and distribution of the article with the strict proviso that no changes or edits are made and the original work is properly cited (including links to both the formal publication through the relevant DOI and the license). See: https://creativecommons.org/licenses/by-nc-nd/4.0/.

\section{References}

1. Pelletier SJ, Guidinger MK, Merion RM, et al. Recovery and utilization of deceased donor kidneys from small pediatric donors. Am J Transplant 2006;6:1646-52.

2. Jiang Y, Song T, Qiu Y, et al. Outcomes of single kidney transplantation from pediatric donors: A single-center experience. Pediatric Transplantation 2018;22:e13196.

3. Satterthwaite R, Aswad S, Sunga V, et al. Outcome of en bloc and single kidney transplantation from very young cadaveric donors. Transplantation 1997;63:1405-10.

4. Friedersdorff F, Fuller TF, Werthemann P, et al. Outcome of single pediatric deceased donor renal transplantation to adult kidney transplant recipients. Urol Int 2014;92:323-7.

5. Hayes JM, Novick AC, Streem SB, et al. The use of single pediatric cadaver kidneys for transplantation. Transplantation 1988;45:106-10.

6. Modlin C, Novick AC, Goormastic M, et al. Long-term results with single pediatric donor kidney transplants in adult recipients. J Urol 1996;156:890-5.

7. Suneja M, Kuppachi S, Katz D, et al. Small Split Pediatric Kidneys to Expand the Donor Pool: An analysis of Scientific Registry of Transplant Recipients (SRTR) Data. Transplantation 2019;103:2549-57.

8. Balachandran VP, Aull MJ, Goris M, et al. Successful Transplantation of Single Kidneys From Pediatric Donors Weighing Less Than or Equal to $10 \mathrm{~kg}$ Into Standard Weight Adult Recipients. Transplantation 2010;90:518-22.

9. Csapo Z, Knight RJ, Podder H, et al. Long-term outcomes of single paediatric vs. ideal adult renal allograft transplants in adult recipients. Clin Transplant 2006;20:423-6.

10. Kayler LK, Magliocca J, Kim RD, et al. Single kidney 
transplantation from young pediatric donors in the United States. Am J Transplant 2009;9:2745-51.

11. Rofaiel G, Allam SR, Ali M, et al. Successful Transplantation of Pediatric Kidneys Despite Vascular Injuries. Cureus 2018;10:e3073.

12. Damji S, Callaghan CJ, Loukopoulos I, et al. Utilisation of small paediatric donor kidneys for transplantation. Pediatric Nephrology 2019;34:1717-26.

13. Sharma A, Fisher RA, Cotterell AH, et al. En bloc kidney transplantation from pediatric donors: comparable outcomes with living donor kidney transplantation. Transplantation 2011;92:564-9.

14. K/DOQI Workgroup. K/DOQI clinical practice guidelines for cardiovascular disease in dialysis patients. Am J Kidney Dis 2005;45:S1-S153.

15. Muscroft L, Zehnder D, Fletcher S, et al. Rapid resolution of severe sustained low blood pressure in haemodialysis patients after successful renal transplantation. Nephrol Dial Transplant 2012;27:4223-7.

16. Ignacak E, Cieniawski D, Betkowska-Prokop A, et al. Beneficial effect of kidney transplantation from a deceased donor on severe chronic refractory intradialytic hypotension - a case report. BMC Nephrology 2017;18:248-53.

17. Reeves PB, Mc Causland FR. Mechanisms, Clinical Implications, and Treatment of Intradialytic Hypotension. Clin J Am Soc Nephrol 2018;13:1297-303.

18. Assimon MM, Flythe JE. Definitions of intradialytic hypotension. Semin Dial 2017;30:464-72.

19. Cases A, Coll E. Chronic hypotension in the dialysis patient. J Nephrol 2002;15:331-5.

20. Rogan A, McGregor G, Weston C, et al. Exaggerated blood pressure response to dynamic exercise despite chronic refractory hypotension: results of a human case study. BMC Nephrol 2015;16:81.

21. Kim TW, Bailard N, Coveler LA. The anesthetic management of a child with chronic hypotension for renal transplantation. J Clin Anesth 2006;18:297-9.

22. Sun CY, Wu MS. Renal transplantation reversed

Cite this article as: Zheng L, Jia H, Wang R, Peng W, Lv J, Lei W, Liu G, Cui Y, Chen J, Wu J. Kidney transplantation from small pediatric donors may be feasible to those who developed chronic refractory dialysis hypotension: a singlecenter experience. Ann Transl Med 2020;8(11):683. doi: 10.21037/atm-20-304 intractable hypotension in a diabetic patient. Diabetes Care 2007;30:e65.

23. Mitrou N, Aquil S, Dion M, et al. Transplantation of pediatric renal allografts from donors less than $10 \mathrm{~kg}$. Am J Transplant 2018;18:2689-94.

24. Mallon DH, Summers DM, Bradley JA, et al. Defining delayed graft function after renal transplantation: simplest is best. Transplantation 2013;96:885-9.

25. Palmer BF. Why are some dialysis patients chronically hypotensive in the absence of heart disease and volume depletion? Semin Dial 2011;24:404-5.

26. Flynn JT, Falkner BE. New Clinical Practice Guideline for the Management of High Blood Pressure in Children and Adolescents. Hypertension 2017;70:683-6.

27. National High Blood Pressure Education Program Working Group on High Blood Pressure in Children and Adolescents. The fourth report on the diagnosis, evaluation, and treatment of high blood pressure in children and adolescents. Pediatrics 2004;114:555-76.

28. Flynn JT, Kaelber DC, Baker-Smith CM, et al. Clinical Practice Guideline for Screening and Management of High Blood Pressure in Children and Adolescents. Pediatrics 2017;140:e20171904.

29. Cases A, Esforzado N, Lario S, et al. Increased plasma adrenomedullin levels in hemodialysis patients with sustained hypotension. Kidney Int 2000;57:664-70.

30. Pape L, Ahlenstiel T, Kanzelmeyer NK. Consequences of the change in Eurotransplant allocation system on kidney allocation in children. Clin Transplant 2013;27:650-1.

31. Wu DA, Watson CJ, Bradley JA, et al. Global trends and challenges in deceased donor kidney allocation. Kidney Int 2017;91:1287-99.

32. Rodríguez Faba O, Boissier R, Budde K, et al. European Association of Urology Guidelines on Renal Transplantation: Update 2018. Eur Urol Focus 2018;4:208-15.

33. Kälble T, Lucan M, Nicita G, et al. EAU guidelines on renal transplantation. Eur Urol 2005;47:156-66. 